\title{
Teaching Practices Game: Interactive Resources for Training Teaching Assistants
}

\author{
Colleen M. Lewis \\ Harvey Mudd College \\ Claremont, CA, USA \\ lewis@cs.hmc.edu
}

\author{
Phillip Conrad \\ University of California, Santa Barbara \\ Santa Barbara, CA, USA \\ phtcon@ucsb.edu
}

\begin{abstract}
In this interactive special session, participants will learn to facilitate a workshop for training teaching assistants (TAs) based on a card game. The game invites players to respond to challenging scenarios that TAs may face in the course of their duties. Each scenario appears on a card, and players discuss how they would respond. Session participants will receive a deck of 52 of these cards created with funding from a SIGCSE Special Projects Grant. This session uses the format of two previous well attended SIGCSE special sessions $[3,4]$ that focused on bias and had a target audience of faculty. While the intended audience is those interested in TA training, everyone interested in inclusive teaching practices is welcome to join in the rich small and large group discussions that we expect to take place!
\end{abstract}

\section{KEYWORDS}

teaching assistants, inclusive teaching, microaggressions

\section{ACM Reference Format:}

Colleen M. Lewis and Phillip Conrad. 2020. Teaching Practices Game: Interactive Resources for Training Teaching Assistants. In The 51st ACM Technical Symposium on Computer Science Education (SIGCSE '20), March 11-14, 2020, Portland, OR, USA. ACM, New York, NY, USA, 2 pages. https: //doi.org/10.1145/3328778.3366989

\section{INTRODUCTION}

With growing enrollment at the college level [1], teaching assistant (TA) staff at the undergraduate level have needed to expand as well. However, with a growing staff it can be more difficult to train and monitor TAs. While there are resources for structuring TA programs and training [5] we know of no widely disseminated TA training materials. The workshop content focuses on building ability within TAs to apply inclusive teaching practices as well as recognize and respond to bias. This is particularly important because research has shown ways in which teachers' biases shape students experiences and opportunities to learn (see [2] for a brief review).

This workshop is structured around a card game similar to the one used in previously well-attended Special Sessions at SIGCSE 2018 and 2019 [3, 4]. In this game, participants take turns responding

Permission to make digital or hard copies of part or all of this work for personal or classroom use is granted without fee provided that copies are not made or distributed for profit or commercial advantage and that copies bear this notice and the full citation on the first page. Copyrights for third-party components of this work must be honored.

For all other uses, contact the owner/author(s).

SIGCSE '20, March 11-14, 2020, Portland, OR, USA

(C) 2020 Copyright held by the owner/author(s)

ACM ISBN 978-1-4503-6793-6/20/03.

https://doi.org/10.1145/3328778.3366989 to a scenario posed on the card, answering the question "What would you do if.... The set of cards used in this session differs from the previous ones that focused on responding to bias, and targeted faculty; the cards for the current session are targeted for training TAs and cover a broad range of relevant topics.

\section{INTENDED AUDIENCE \& SESSION GOALS}

The intended audience is faculty, staff, or TAs who would be interested in replicating the workshop for TAs at their institution. We hope to achieve the following goals:

- Goal 1: Prepare participants to replicate the Teaching Practices Game workshop at their institution.

- Goal 2: Engage in lively discussions of inclusive teaching practices where participants can learn from each other.

- Goal 3: Build community and connections among SIGCSE attendees.

As a secondary audience, we expect that educators may be interested in attending the session for the lively discussion and learning related to inclusive teaching practices. We believe that both sets of participants will be well served by the session.

Based on our experience with the same format at SIGCSE 2018 and 2019, the special session format allows sufficient time for the participants to learn the game, play several rounds, and then debrief afterwards [3, 4].

\section{SESSION OUTLINE}

As participants arrive, we will be encouraging them to form groups of three to six. This provides an initial opportunity for participants to interact and make connections. The session will be organized as follows:

- 15 min Introduction and game rules

- 20 min Participants play Round 1

- 20 min Whole group discussion

- 20 min Participants play Round 2

- 10 min Whole group discussion

\subsection{Introduction and Game Rules}

Once the session has started we will introduce the goals for the session as stated above. Next, we will model a single round of the game and will introduce the game rules:

(1) One person (the "Leader" for this round) draws a card and reads the bold text at the top.

(2) The leader then asks the group: What would you do in that situation? Each member of the group answers the question or passes. 
(3) After hearing all answers (or 3 minutes), the Leader reads the sample answer from the card aloud and picks their favorite answer (the "winner"). The "winner" keeps the card to tally who won the most times.

(4) The leader rotates clockwise.

For convenience, we will leave these rules displayed while participants play the game.

\subsection{Round 1: Inclusive Teaching Practices}

After this approximately 10-minute introduction, participants will have 20 minutes to play cards from Round 1 of the Teaching Practices Game. These cards relate to inclusive teaching practices, as illustrated in the example cards below (these are samples, not a full list):

There are 29 cards available in Round 1; we expect that in 20 minutes, most groups will discuss only 5-10. Fortunately, participants will be able to take copies of the game so that they can continue to review the cards and ultimately host a similar workshop for TAs at their institution.

Here is a sample of the Round 1 Scenarios: cards:

- No one needs help when you arrive to your office hours (or open lab hours).

- A student asks for help with their code, then goes on their phone while you are looking at the code

- A student compares their abilities to yours and is feeling inadequate.

- A student becomes overwhelmed and cries because their code isn't working.

- A student seems to just want you to tell them the answer.

- Students are asking for help past the end of your scheduled lab time.

- A fellow TA is constantly on their phone rather than paying attention to students during lab.

- A student has tons of compilation errors and asks for help.

- Students in your class seem embarrassed when they get something wrong.

- You catch a student copying another students' homework. It is due in 20 minutes and they are in a panic.

- During class a student with a lot of prior CS experience asks questions about advanced topics outside of the scope of the class content.

- You see two students pair programming, but only one of them is working.

- A student reports that their team member hasn't been following through on their assigned tasks.

\subsection{Whole Group Discussion \& Introduction to Round 2}

For approximately 10 minutes, we will pass a microphone around the room to hear observations from participants and solicit questions. From our experience, participants are more frequently stumped by scenarios in Round 2. As a result, we will provide them four strategies for responding:

(1) What makes you say that?

(2) Wow, I don't know what to say.
(3) I used to think about it like that, but now...

(4) I can see why you might say that, but...

\subsection{Round 2: Recognizing \& Responding to Bias}

Next, with the recommended strategies from above displayed on the projector, participants will have 20 minutes do play the game with the 23 cards from Round 2. As with Round 1, we expect that participants will have time to play through 5-10 of these, but will be able to take the full deck home with them.

Here is a sample of the Round 2 Scenarios:

- Someone seems to frequently interrupt women when they are speaking.

- Someone says "women just aren't interested in CS."

- Someone says: "Sexism used to be so much worse. People these days make a big deal about the smallest things!"

- A student says that it's unfair that some students get extra time on exams just because they have a "so-called disability".

- A TA says "It is tough TA-ing for a woman professor because women are so emotional."

- Someone says to an international student: "Your name is so hard to pronounce. I'll never remember it. Can I call you something else?"

- Someone says "I can't be racist! I'm a good person."

- A students says "There are so few Black and Latinx students in CS; it is a lot easier for them to get CS jobs."

- Someone says "Jack says he uses the pronoun 'they,' but I told him that it isn't grammatically correct."

- Someone says "It is great to have women on teams, they're so collaborative."

- Someone says "People should just tell me if I say something that offends them."

- A student says: "Girls in CS classes must get asked out all the time. So many guys. Must be great!"

- Someone says "If anyone works hard, they'll be able to get ahead."

\section{ACKNOWLEDGMENTS}

These workshop materials were created with funding from a SIGCSE Special Projects Grant in 2018 and funding from the National Science Foundation (1339404 and 1821136).

\section{REFERENCES}

[1] Tracy Camp, W. Richards Adrion, Betsy Bizot, Susan Davidson, Mary Hall, Susanne Hambrusch, Ellen Walker, and Stuart Zweben. 2017. Generation CS: The Growth of Computer Science. ACM Inroads 8, 2 (May 2017), 44-50. https://doi.org/10. $1145 / 3084362$

[2] Colleen M Lewis. 2017. ACM RETENTION COMMITTEE Twelve tips for creating a culture that supports all students in computing. ACM Inroads 8, 4 (2017), 17-20.

[3] Colleen M Lewis, Catherine Ashcraft, and Kyla McMullen. 2018. What Would You Say if...: Responding to Microaggressions, Bias, and Other Nonsense. In Proceedings of the 49th ACM Technical Symposium on Computer Science Education. ACM, 132133.

[4] Colleen M Lewis, Wendy M DuBow, and Kyla McMullen. 2019. Leading Conversations about Microaggressions, Bias, and Other Difficult Topics. In Proceedings of the 50th ACM Technical Symposium on Computer Science Education. ACM, 805-806.

[5] Diba Mirza, Phillip T. Conrad, Christian Lloyd, Ziad Matni, and Arthur Gatin. 2019. Undergraduate Teaching Assistants in Computer Science: A Systematic Literature Review. In Proceedings of the 2019 ACM Conference on International Computing Education Research (ICER '19). ACM, New York, NY, USA, 31-40. https: //doi.org/10.1145/3291279.3339422 